\title{
ВЛИЯНИЕ ДЕМОГРАФИЧЕСКИХ ИЗМЕНЕНИЙ НА СИСТЕМУ ЧАСТНЫХ МЕЖПОКОЛЕННЫХ ТРАНСФЕРТОВ
}

\author{
АННА МИРОНОВА
}

\begin{abstract}
В статье рассматриваются последствия демографических изменений для системы частных межпоколенных трансфертов. Выявлены основные демографические факторы частных межпоколенных трансфертов, среди которых изменение в возрастной структуре населения, распространённость разводов, повторных браков, незарегистрированных союзов, повышение миграционной активности населения, процесс нуклеаризаџии, а также проанализировано их влияние на систему частных межпоколенных трансфертов.
\end{abstract}

Ключевые слова: семья, частные межпоколенные трансферты, межсемейные обмены, демографические изменения, домохозяйства.

Взаимная поддержка между поколениями в рамках семьи составляет основу не только семейных отношений, но также и всей системы общественного благосостояния. Так, родители продолжают поддерживать своих детей не только в период взросления, но и когда те становятся самостоятельными и покидают родительский дом. В свою очередь дети помогают родителям в трудных ситуациях - например, заботятся о них во время болезни.

Обмены различными видами благ и услуг между поколениями на безвозмездной основе обозначаются общим термином «трансферты». Особенность частных трансфертов, в отличие от социальных, состоит в том, что ресурсы перераспределяются по неформальным каналам. К последним можно отнести родственные каналы, а также каналы дружеской и приятельской поддержки. Однако, несмотря на существующее разнообразие возможных каналов передачи частных трансфертов, основные потоки перераспределяются между родственниками и именно в межпоколенной плоскости, что подтверждается имеющимися исследованиями [Барсукова 2004] и данными [РМЭ3 2013] (Российский мониторинг экономического положения и здоровья населения - НИУ ВШЭ; рисунок 1). Принимая во внимание межпоколенный аспект, выделяют нисходящие (от представителей старшего поколения младшему) и восходящие (от младшего поколения старшему) трансферты.

\footnotetext{
АННА АЛЕКСЕЕВНА МИРОНОВА (amironova@hse.ru), НАЦИОНАЛЬНЫЙ ИССЛЕДОВАТЕЛЬСКИЙ УНИВЕРСИТЕТ «ВЫСШАЯ ШКОЛА ЭКОНОМИКИ», РОссия.

СТАТЬЯ ПОДГОТОВЛЕНА В ХОДЕ ПРОВЕДЕНИЯ ИССЛЕДОВАНИЯ В РАМКАХ ПРОГРАММЫ ФУНДАМЕНТАЛЬНЫХ ИССЛЕДОВАНИЙ НАЦИОНАЛЬНОГО ИССЛЕДОВАТЕЛЬСКОГО УНИВЕРСИТЕТА «ВЫСШАЯ ШКОЛА ЭКОНОМИКИ» (НИУ ВШЭ) И С ИСПОЛЬЗОВАНИЕМ СРЕДСТВ СУБСИДИИ НА ГОСУДАРСТВЕННУЮ ПОДДЕРЖКУ ВЕДУЩИХ УНИВЕРСИТЕТОВ РОССИЙСКОЙ ФЕДЕРАЦИИ В ЦЕЛЯХ ПОВЫШЕНИЯ ИХ КОНКУРЕНТОСПОСОБНОСТИ СРЕДИ ВЕДУЩИХ МИРОВЫХ НАУЧНООБРАЗОВАТЕЛЬНЫХ ЦЕНТРОВ.
}

СТАТЬЯ ПОСТУПИЛА В РЕДАКЦИЮ В ДЕКАБРЕ 2015 Г. 
В зависимости от типа передаваемой помощи выделяют материальные и инструментальные трансферты. Материальные трансферты представляют собой совокупность финансовых и собственно материальных трансфертов. Инструментальные трансферты - это перераспределение времени между поколениями, выражающееся в потоках различных услуг. В рамках инструментальных трансфертов зачастую в качестве отдельного подвида выделяют функциональные трансферты, которые представляют помощь людям, утратившим способность самостоятельно ухаживать за собой в результате болезни.

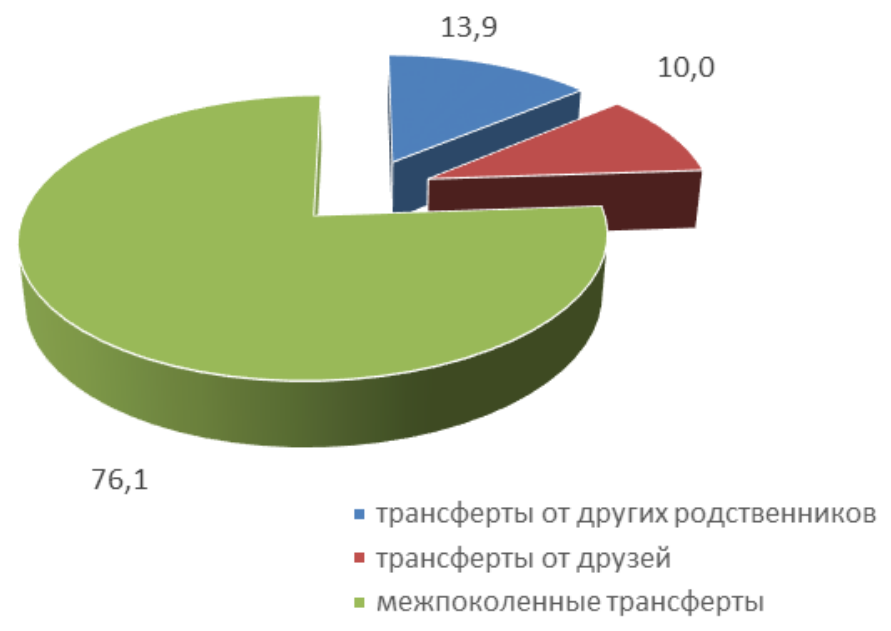

Рисунок 1. Распределение получаемых частных трансфертов на межпоколенные и другие, \%

Примечание: К межпоколенным были отнесень трансферты от родителей, детей, прародителей и внуков. При этом трансферты от других родственников и от друзей не исключают межпоколенного измерения.

Источник: [РМЭЗ 2013].

Совокупность актов передачи и получения помощи, распределяемой между поколениями, условно обозначим системой частных трансфертов. Систему частных межпоколенных трансфертов можно анализировать на индивидуальном уровне, уровне семьи и общества в целом. В зависимости от уровня анализа можно выделять различные факторы частных межпоколенных трансфертов (таблица 1).

Таблица 1. Типология факторов частных межпоколенных трансфертов

\begin{tabular}{lll}
\hline \multicolumn{4}{c}{ Факторы частных межпоколенных трансфертов } \\
\hline \multicolumn{1}{c}{ индивидуальный уровень } & уровень семьи (домохозяйства) & \multicolumn{1}{c}{ социетальный уровень } \\
\hline- возраст & - структура домохозяйства, & - развитость государственных \\
- пол & которая определяется наличием & (пенсионное обеспечение, система \\
- состояние здоровья & несовершеннолетних детей и их & социльного обслуживания, меры \\
- образование & числом, возрастом главы & негосударственных \\
- статус занятости & домохозяйства, наличием & (благотворительные организации, \\
- семейное положение & семейного ядра и его типом & добровольное социальное \\
- уровень дохода & (супружеская пара, неполная & страхование и др.) институтов \\
- территориальная & семья) и т.д. & социальной защиты населения \\
удалённость от родственников & - размер домохозяйства & - культурные нормы \\
\hline
\end{tabular}


В рамках данного исследования мы ограничиваемся анализом частных межпоколенных трансфертов на уровне семьи. При этом рассмотрение частных трансфертов на этом уровне в основном сводится к характеристикам домохозяйства, так как имеющиеся статистические данные относятся именно к ним. Однако строго говоря, наиболее полное представление о частных межпоколенных трансфертах на семейном уровне можно получить, обладая информацией не только о характеристиках домохозяйств, но и о структуре семейной группы в целом: о совокупности живущих в данный момент времени родственников, которые чаще всего принадлежат к различным домохозяйствам. С этой точки зрения тип домохозяйства представляет собой характеристику особенностей проживания членов родственной группы, а состав родственной группы даёт представление о потенциальных участниках частных межпоколенных обменов.

Проанализируем подробнее демографические детерминанты, влияющие на состав родственных домохозяйств. Логика такого влияния представлена на рисунке 2.

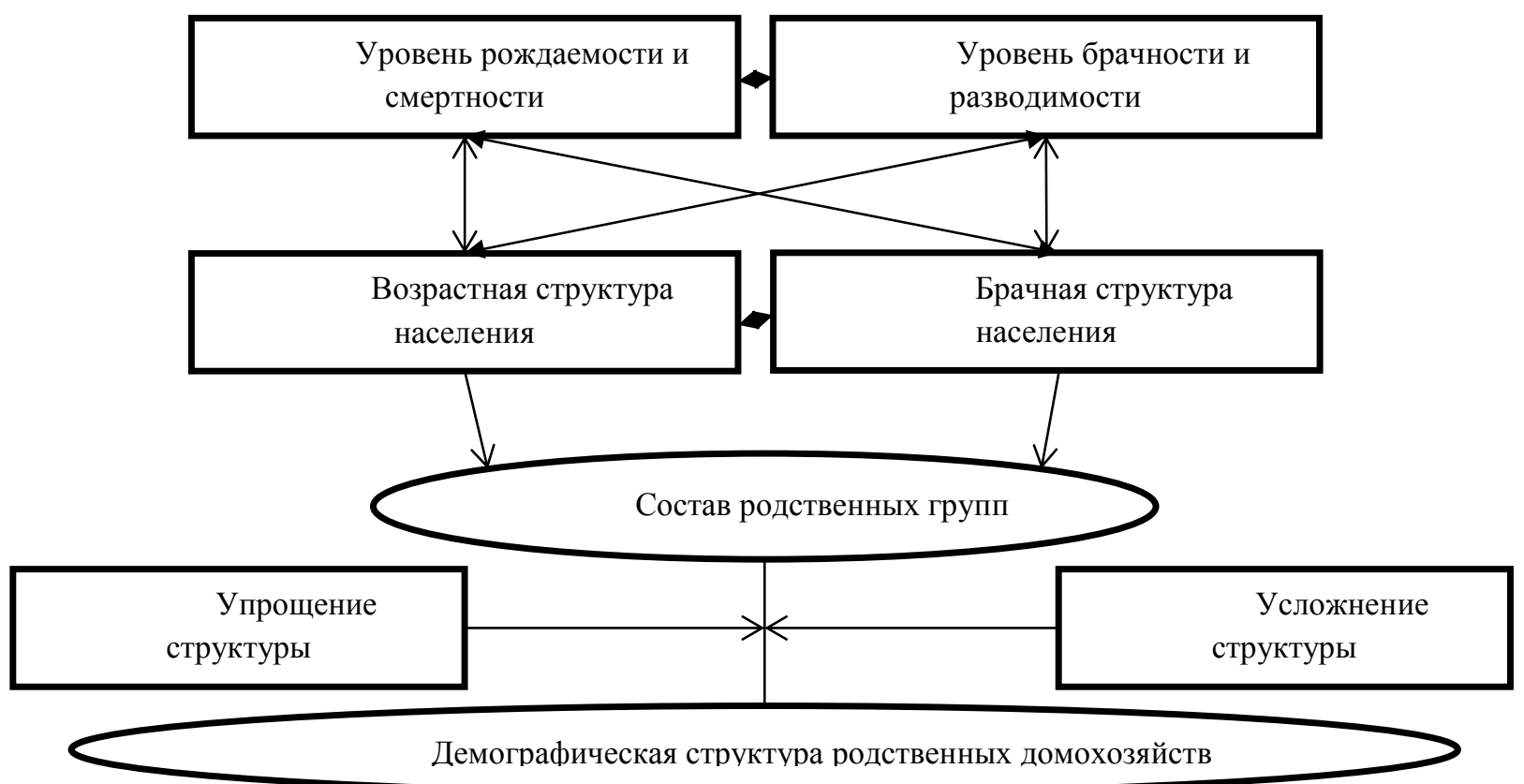

\section{Рисунок 2. Связь между демографическими детерминантами и демографической структурой родственных домохозяйств}

Демографическими детерминантами состава родственной группы, внутри которой происходит обмен межпоколенными трансфертами, являются возрастно-половая и брачная структуры населения. В свою очередь демографическая структура (возрастно-половая и брачная) является результатом действия демографических процессов в прошлом (рождаемости и смертности, брачности и разводимости) и в то же время сама оказывает на них влияние. Члены родственной группы могут расселяться по разным домохозяйствам, что связано с процессом упрощения структуры домохозяйства, или наоборот объединяться в одно домохозяйство, усложняя его структуру. 
Проанализируем подробнее демографические детерминанты, влияющие на состав родственной группы в целом и родственных домохозяйств в частности, а также последствия этого влияния для системы частных межпоколенных трансфертов.

Изменение в возрастной структуре населения определяется особенностями режимов рождаемости и смертности и проявляется в трансформации жизненного цикла человека, изменении состава родственных домохозяйств. Возрастная структура населения России за последние 100 с лишним лет существенно изменилась: возрос удельный вес населения в средних и старших возрастах, а доля детского населения сократилась (рисунок 3). Возрастная пирамида родственной группы меняет свою форму аналогично пирамиде всего населения. Снижение уровня рождаемости и увеличение продолжительности жизни, проявившееся в трансформации возрастной структуры, ведёт к росту числа одновременно живущих в семье поколений (вертикальное расширение семьи), в то время как число представителей одного поколения снижается (горизонтальное сужение). Такие структурные изменения ведут к тому, что, с одной стороны, забота о пожилых членах семьи ложится на плечи меньшего числа представителей младшего поколения, а с другой потенциал поддержки молодого поколения возрастает. Как показывают исследования, сужение семьи по горизонтали связано с усилением нисходящего частного межпоколенного потока [Alter 2013].

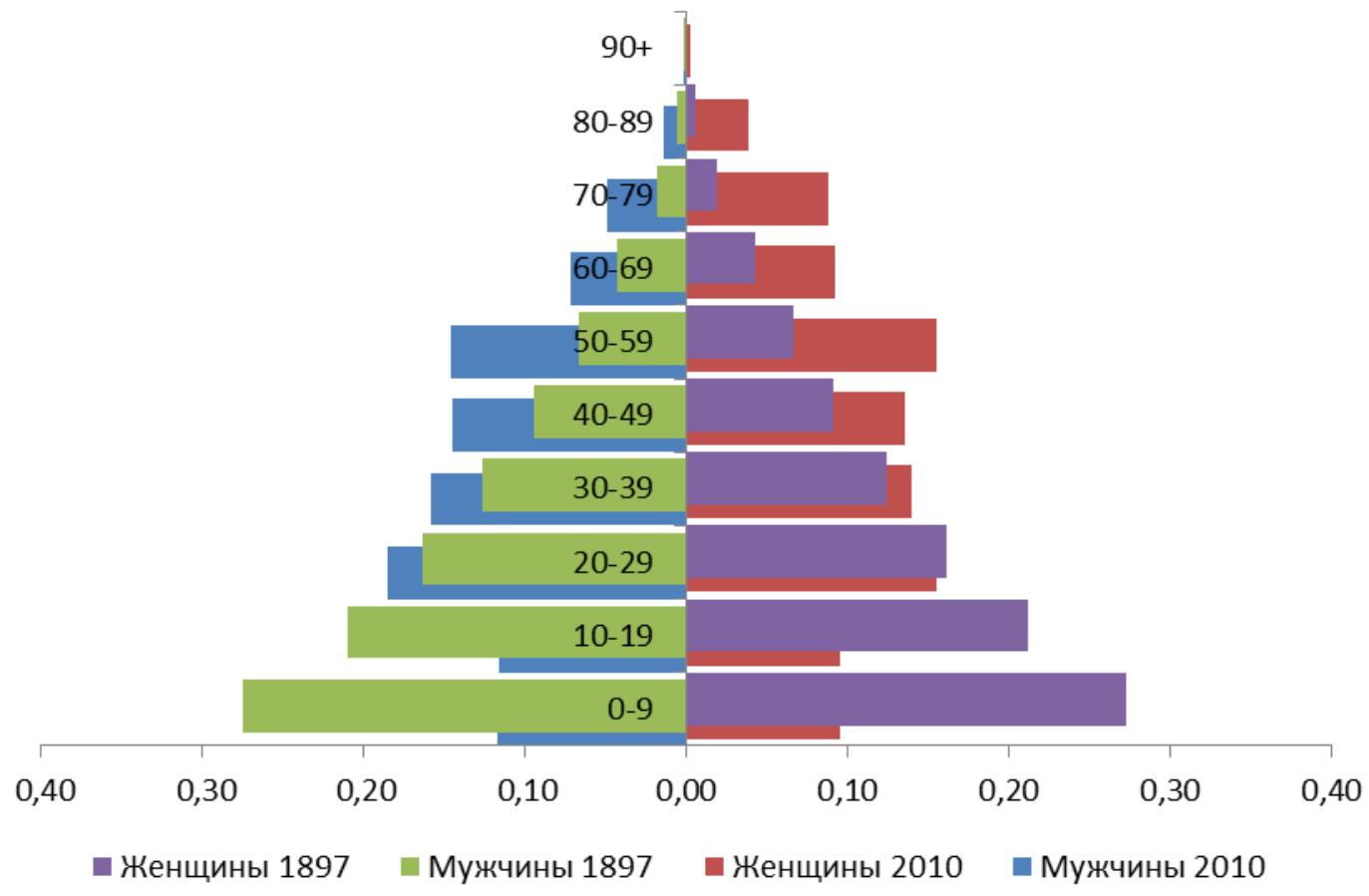

\section{Рисунок 3. Половозрастное распределение населения России по переписи 1897 и 2010 г.}

Источник: [Перепись Российской Империи... 1905; Всероссийская перепись населения 2010].

Вместе с тем в связи с ростом продолжительности жизни родителей все больше откладывается возраст, когда дети получают наследство. Несмотря на то, что изменение ожидаемой продолжительности жизни в России за последние 50 лет нельзя 
охарактеризовать как период перманентного роста (рисунок 4), за последние 10 лет наметился восстановительный восходящий тренд.

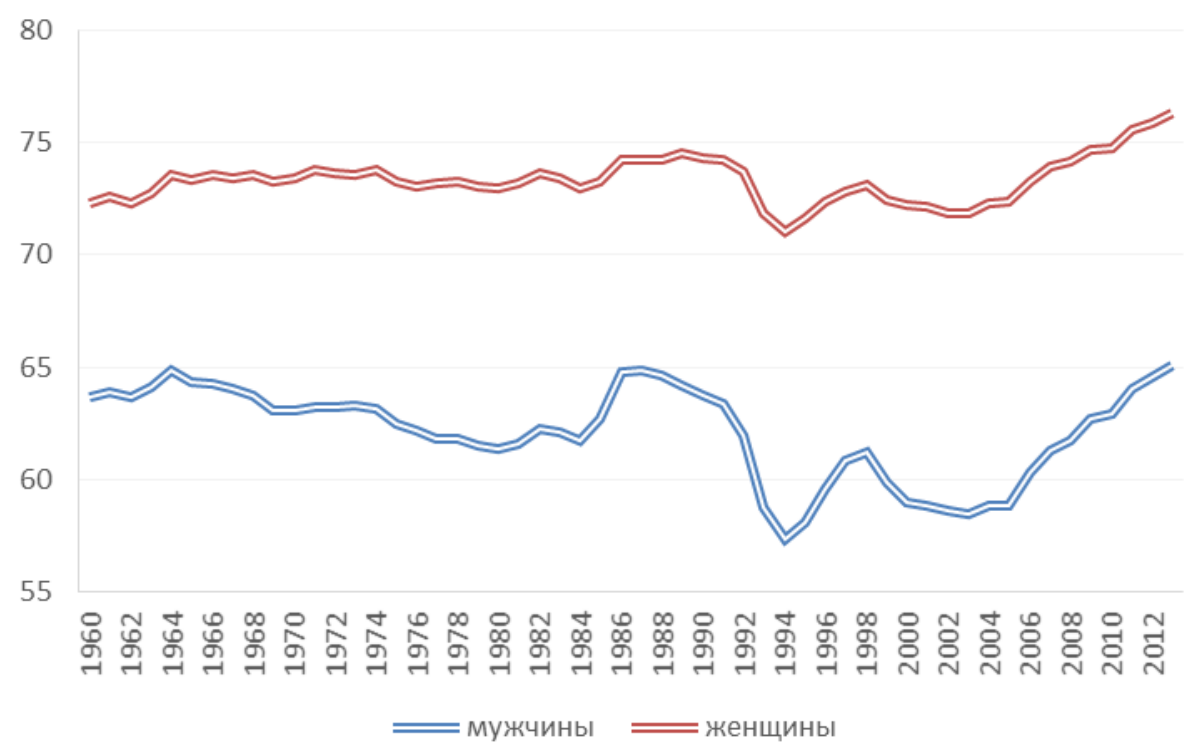

Рисунок 4. Ожидаемая продолжительность жизни при рождении в России, 1960-2013

Источник: [Приложение Демоскоп Weekly 2016].

По имеющимся оценкам, в России за последние 100 лет возраст получения наследства повысился в среднем с 35 до 50 лет [Вишневский 2005]. Откладывание момента получения наследства изменяет характер взаимодействия младшего поколения со старшим. Например, Котликов и Спивак [Kotlikoff, Spivak 1981] рассматривают наследство или обещание его как подразумеваемый межпоколенный контракт, предполагающий родительский контроль над семейным благосостоянием и основанный на доверии со стороны детей к тому, что родители наградят их за поддержку посмертным даром. Некоторые исследователи [Bernheim, Shleifer, Summers 1985] приходят к выводу, что контакты между родителями и детьми происходят чаще в том случае, когда родители имеют большее потенциальное наследство. Суссман и коллеги [Sussman, Cates, Smith 1970] объясняют эту ситуацию на основе принципа реципроктности. Они считают, что дети часто проявляют заботу о своих родителях в ожидании, что в перспективе они завладеют большей частью родительской собственности. В связи с этим родители могут использовать своё имущество как стратегический потенциал для мотивации детей к поддержке. Тогда увеличение продолжительности жизни в старших возрастах можно рассматривать как период, когда родители растрачивают потенциальное наследство своих детей. В традиционных обществах считалось, что перспектива получения наследства или, если более точно, угроза его неполучения действует как стимулирующий механизм, посредством которого глава семьи использует труд своих сыновей в хозяйстве. Зачастую основной предполагаемый наследник оказывался в довольно трудном положении. Как отмечает Р. Зидер [Зидер 1997], родители требовали от будущего наследника участия во всех хозяйственных вопросах, а также поддержку в старости. С этой точки зрения увеличение продолжительности жизни главы семьи может снизить ценность наследства как одной из форм межпоколенных трансфертов [Rozenzweig 1994]. С другой стороны, чем 
дольше живут родители, тем выше размер потенциального наследства, которое они могут накопить, тем дольше они смогут помогать своим детям при жизни. Кроме того, при низкой рождаемости наследство распределятся между одним-двумя наследниками-детьми, а не тремя и более, как было раньше.

В условиях роста ожидаемой продолжительности жизни изменяется структура жизненного цикла человека: увеличивается число лет, прожитых в средних и старших возрастах. Изменяются границы между тремя основными этапами жизненного цикла: образование, работа, период незанятости. Если рассматривать удельный вес каждого этапа в условиях роста продолжительности жизни, то можно отметить следующие тенденции: длительность периода жизни, связанного с обучением, возрастает; период трудовой активности сокращается; период жизни, проведённый на пенсии, удлиняется.

Смена выделенных этапов жизни характеризуется высокой степенью гибкости. Например, на этапе трудовой активности современному человеку часто приходится периодически учиться, подстраиваясь под новые изменения, и развивать свои навыки. Например, в Европе (ЕС-27) неуклонно растёт доля взрослого населения в возрасте от 25 до 64 лет, которые указали, что продолжают получать образование - проходят обучение или профессиональную подготовку. С 2000 до 2014 г. данный показатель возрос с 7 до 11\%. Данный феномен в современных исследованиях обозначается как непрерывное образование или образование на протяжении всей жизни (lifelong learning). По достижении пенсионного возраста человек также может продолжить учиться или работать. В России значительная доля как мужчин (27\%), так и женщин (30\%) в 2013 г. продолжали оставаться занятыми на рынке труда после достижения пенсионного возраста, причём данный показатель растёт [Экономическая активность населения... 2014]. Изменение в соотношении соответствующих периодов жизни связано с трансформацией паттернов, касающихся образования, работы, семьи и здоровья: увеличение продолжительности обучения, откладывание родительства, снижение рождаемости, более позднее вступление в трудовую деятельность с полным рабочим днём, меньшая продолжительность занятости, постепенный (плавный) выход на пенсию [Вишневский 2005]. Таким образом, жизненный цикл становится более гибким и допускает многовариантность, что связано с появлением дополнительных рисков. Ввиду этого родственная поддержка приобретает особую актуальность.

Вместе с изменением границ между этапами жизненного цикла происходит трансформация представлений о порогах наступления того или иного этапа в жизни. Знание людьми своего календарного возраста является достижением индустриальной эпохи, когда произошло законодательное закрепление возрастных норм. Однако представление о социальном возрасте, который связан с определённой стадией жизненного цикла, существовало всегда. Например, старость всегда ассоциировалась с ослаблением физических сил, нетрудоспособностью и потребностью в опеке. Порог старости не остаётся постоянным во времени и одинаковым для разных стран. В процессе демографических изменений восприятие стадий жизненного цикла изменилось. В начале 1970-х годов американские геронтологи Б. Нейгартен и Э. Шанас впервые разделили пожилых на две группы: молодых стариков (the Young Old) и старых стариков (the Old Old) [Neugarten 1974]. В 1990-е годы английский демограф Питер Ласлетт предложил разделить жизненный цикл 
современного человека на 4 стадии: детство, взрослость, «третий возраст» и «четвертый возраст» [Laslett 1990; 1996]. Современные «Молодые старики» (люди третьего возраста до 75 лет) характеризуются хорошим для своего возраста здоровьем, относительно высоким уровнем образования и благосостояния (за счёт накопленных средств и получаемых пенсий), энергичностью и активностью. Традиционному образу стариков соответствуют люди «четвёртого возраста», которые испытывают необходимость в поддержке. В России, по мнению экспертов [Денисенко 2005], слой людей «третьего возраста» до конца еще не сформировался. Однако в целом и в России возраст 75 лет является неким рубежом. Так, до 75 лет большинство пожилых считают себя относительно здоровыми, и только после 75 доля тех, кто не удовлетворён своим здоровьем, начинает превышать долю тех, кто им в той или иной степени удовлетворён (таблица 2). При переходе к возрастной группе «75 лет и старше» доля тех, кто прибегает к помощи других лиц для самообслуживания, резко возрастает (на 21,3\%) и составляет почти 50\%. Также среди лиц в возрасте 75 лет и старше уровень образования существенно ниже, чем среди других выделяемых возрастных групп: подавляющее большинство из них имеют только общее образование (65\%). Таким образом, при оценивании последствий роста ожидаемой продолжительности жизни с точки зрения изменения нагрузки пожилыми людьми необходимо учитывать возможное смещение возрастных границ наступления старости: люди стали жить дольше, но и старость в понимании немощности теперь может наступать позже. Если члены семьи стали жить дольше, это не обязательно значит, что теперь старшее поколение дольше обременяет младшее, так как порог старости отодвигается.

Таблица 2. Субъективная оценка состояния здоровья и уровень образования по возрастным группам, \%

\begin{tabular}{l|r|r|r|r|r}
\hline & \multicolumn{5}{c}{ Возраст, лет } \\
\cline { 2 - 6 } & $55-59$ & $60-64$ & $65-69$ & $70-74$ & 75 и старше \\
\hline Состояние здоровья: & & & & & \\
очень хорошее & 0,6 & 0,4 & 0,3 & 0,2 & 0 \\
хорошее & 14,7 & 9,6 & 4,6 & 3,3 & 1,9 \\
удовлетворительное & 71,5 & 73,1 & 72,1 & 61,3 & 46,2 \\
плохое & 12,1 & 15,9 & 21,9 & 32,0 & 45,5 \\
очень плохое & 1,1 & 1,1 & 1,2 & 3,1 & 6,4 \\
Доля тех, кто прибегает к помощии других & 17,6 & 18,9 & 19,8 & 26,3 & 47,6 \\
для самообслужсивания & & & & & \\
Уровень образования: & 22,1 & 22,7 & 21,0 & 17,1 & 11,6 \\
высшее & 45,3 & 42,2 & 33,4 & 28,5 & 19,4 \\
среднее специальное & 32,4 & 34,8 & 45,1 & 53,5 & 65,2 \\
общее & 0,2 & 0,3 & 0,5 & 0,9 & 3,7 \\
не имеющие начального образования & &
\end{tabular}

Источник: [Всероссийская перепись населения 2010, ВНДН 2012].

На фоне изменения границ между этапами жизненного цикла люди все чаще откладывают родительство на более поздние возраста. Так, в России с 2000 по 2012 г. средний возраст матери при рождении первого ребёнка возрос с 23,5 до 25 лет [Приложение Демоскоп Weekly 2016]. В связи с этим растет возрастной разрыв между поколениями. Это ведет к тому, что, когда родители постареют и будут нуждаться в помощи, их дети будут ещё незрелыми. С одной стороны, молодые дети более здоровы и имеют больше сил для оказания поддержки родителям, а с другой - в этом возрасте у детей может быть много забот 
о собственных детях, что будет снижать их потенциальные возможности для поддержки родителей.

В связи с тем, что люди стали жить дольше, всё большее число семей может сохранять свою структуру на протяжении более длительного времени, чем это было раньше. В прошлом трехпоколенные семьи встречались, но существовали недолго из-за низкой продолжительности жизни стариков. В результате значительного роста продолжительности жизни в развитых странах увеличилось время сосуществования представителей трех и даже четырех поколений. Рост ожидаемой продолжительности жизни означает, что человек может дольше сохранять статус ребёнка, родителя, супруга [Watkins, Menken, Bongaarts 1987]. Как показывают исследования [Никитенко 1979], в России XIX века мать в среднем с момента появления ребёнка проживала ещё 34 года (т.е. 34 года совместного проживания в одном историческом пространстве), в 70-х годах XX века этот показатель составил 48 лет. За это время средняя продолжительность жизни женщины в статусе бабушки возросла с 12 до 24 лет.

В связи с описанной тенденцией в семье происходит трансформация структуры иждивенцев. Так, «во все века люди знали, что на их иждивении находятся дети. Стариков было мало и нагрузка ими была незначительна (в России в 1897 году на одного человека в возрасте 70 лет и старше приходилось 15 детей до 15 лет). Теперь всё изменилось в противоположную сторону... В прошлом средний возраст детей к моменту смерти одного из родителей составлял 14 лет. Сейчас средний возраст сына к моменту смерти отца приближается к 55-60 годам» [Вишневский 2005]. Вот как А.В. Чаянов описывает жизненный цикл крестьянской семьи: «в первые годы по мере роста семьи она отягощается всё больше и больше неработоспособными домочадцами. Наблюдается быстрое увеличение отношения числа едоков к числу работников. На 15-й год в помощь к родителям поступает их первый ребёнок. По мере взросления детей величина отношения числа едоков к числу работников будет стремительно падать, приближаясь к единице. Соотношение числа едоков к числу работников достигает 1 примерно на 37 году существования семьи» [Чаянов 1989: 215]. В настоящее время положение значительно изменилось. И хотя ситуация в России пока далека от картины Америки 2030 г., которую нам рисуют Л. Котликофф и С. Бернс: «Перед Вами страна, где в колясках выгуливают больше стариков, чем младенцев. Перед Вами страна, в которой количество пенсионеров выросло вдвое, а количество работающих, которые их содержат, - только на 15\%. Перед Вами страна с большим числом обедневших стариков, прозябающих в переполненных, страдающих от недостатка обслуживающего персонала домах престарелых» [Котликофф, Бернс 2005: 18], - но тенденцию к увеличению нагрузки пожилыми нельзя отрицать. Согласно данным ООН в 2010 г. демографическая нагрузка пожилыми в России составила 17 промилле, к 2030 г. прогнозируемое значение этого показателя составит 27 промилле. Одновременно с этим нагрузка детьми имеет тенденцию к снижению. Так, в 1990 г. показатель демографической нагрузки детьми в России составлял 34 промилле, в 2010 г. - 21 промилле. При этом необходимо отметить, что дети и старики представляют собой качественно разные категории иждивенцев. Можно было бы предположить, что в процессе трансформации структуры иждивенцев рост доли пожилых иждивенцев компенсируется снижением доли молодых. Однако А. Сови приходит к выводу, что данное предположение не 
подтверждается на практике по трём основным причинам: потребности детей меньше потребностей стариков (прожиточный минимум по возрастам); за счёт увеличения продолжительности обучения происходит рост нагрузки детьми (средний возраст выхода на рынок труда); передача средств старикам является естественной, но менее мотивированной семейными узами по сравнению с затратами на детей [Сови 1977].

В связи с «вертикальным» расширением семья все чаще сталкивается с необходимостью заботы о пожилых родственниках. Возрастает число пожилых людей, нуждающихся в поддержке, следовательно растёт и доля потенциальных реципиентов восходящей линии трансфертов. Помимо потребности в материальном обеспечении, которая чаще всего обеспечивается за счет государственных пенсий, пожилые люди нуждаются в эмоциональной поддержке, а с возрастом - в функциональной помощи. Эта потребность в основном реализуется в семье. Как показывают исследования [Лежнина 2010], в России слабо распространены объединения пожилых людей, способствующие социализации и противодействующие социальному исключению. Таким образом, на фоне роста демографической нагрузки пожилыми (макроуровень) происходит одновременно увеличение «спроса» на функциональную, инструментальную и эмоциональную поддержку, которая обеспечивается в рамках семьи (микроуровень). Особую значимость инструментальная поддержка со стороны молодого поколения приобретает в условиях быстрого развития информационных и компьютерных технологий. Пожилым людям зачастую трудно разобраться в новых требованиях, которые выдвигает век информационных технологий. Так, например, чтобы разобраться с оплатой за коммунальные услуги, пожилые люди вынуждены обращаться за помощью к своим детям или внукам [Beard et al. 2012].

Ситуация растущего «спроса» на функциональную, инструментальную и эмоциональную поддержку усугубляется растущей долей бездетных женщин, которым нельзя будет рассчитывать на помощь младшего поколения. В России доля окончательно бездетных женщин долгое время оставалась очень низкой по сравнению с западными странами - на уровне 5-7\%. Однако в настоящее время наметилась тенденция к росту данного показателя: для тех поколений женщин, которые на данный момент завершают свою репродуктивную биографию, доля окончательно бездетных приближается к $10 \%$ [Тындик 2015]. При этом всё чаще бездетность обусловлена не проблемами со здоровьем, а личным выбором женщины, что во многом связано с углублением процесса эмансипации женщин. В развитых странах женщины всё чаще делают выбор в пользу карьеры, ограничивая число рождений, а иногда и вовсе отказываясь от семьи. Что касается России, то тенденция к распространению добровольной бездетности среди женщин вполне может стать реальностью в ближайшем будущем. «Еще совсем недавно специалисты отмечали, что одно из главных отличий России от стран Запада заключается в высокой и практически неизменной вероятности рождения хотя бы одного ребенка - откладывание рождения первенца и, тем более, добровольная бездетность в России не были распространены. Сегодня мы уже можем утверждать, что, по крайней мере, первая характеристическая особенность традиционной модели рождаемости для России уже не актуальна приобщение к опыту откладывания первого ребенка среди молодых поколений происходит весьма интенсивно... Обернется ли откладывание рождений для более или менее 
значительной части населения добровольным отказом от материнства навсегда, пока не известно. В то же время по опыту других стран нельзя не иметь в виду возможность некоторого увеличения пропорции ни разу не рожавших женщин» [Захаров 2005]. Согласно имеющимся оценкам [Фрейка, Захаров 2014] в России процесс откладывания деторождения начался с когорт 1960-х годов рождения. При этом уровень компенсации отложенных рождений для поколений, завершающих репродуктивную биографию, является низким, особенно это касается компенсации первых рождений. Так, например, для когорты 1975 года рождения уровень компенсации отложенных рождений составит около 40\% для первых рождений, 50\% для вторых рождений, $60 \%$ для третьих и последующих рождений.

Во всех странах как развитых, так и развивающихся, пожилые люди сталкиваются с рядом трудностей: нехватка финансовых ресурсов, плохое здоровье, потребность в функциональной поддержке. Однако при этом нельзя однозначно сказать, что пожилые люди всегда находятся в более сложном положении, чем представители других возрастных групп. Например, в Америке уровень бедности среди пожилых людей в 1960 г. составлял $35 \%$, а менее чем через 40 лет этот показатель составил всего 10\%, что меньше, чем среди не пожилых. В Колумбии, Коста-Рике и Индии уровень бедности среди пожилых людей не выше, а иногда и ниже, чем для всей страны в целом [Beard et al. 2012]. В России доля малоимущих среди мужчин в возрасте от 31 до 59 лет в 2013 г. составила 19,2\% (среди женщин в возрасте от 31 до 54 лет - 19,9\%), в то время как среди пенсионеров данный показатель значительно ниже: среди мужчин пенсионного возраста - 2,7\%, среди женщинпенсионерок - 7,4\%. Самая высокая доля малоимущих в 2013 г. зафиксирована среди молодёжи от 16 до 30 лет - 22,5\% [Распределение малоимущего населения... 2012]. Почему пожилые люди зачастую в большей степени защищены с точки зрения материальной обеспеченности, чем представители других возрастов? Во многом это связано с тем, что пожилые люди меньше, чем молодые, зависят от неустойчивости на рынке труда. Обеспечение пожилых людей, как правило, складывается из личных сбережений, государственных пособий в виде пенсии, а также в некоторой степени из семейных трансфертов.

Другой важной демографической детерминантой состава родственной группы является брачная структура населения. Как видно из таблицы 3, за последние 100 с лишним лет произошла существенная трансформация структуры населения по брачному состоянию. Вступление в брак откладывается на всё более поздние возраста: в 2010 г. в возрастной группе 20-29 лет 42\% женщин и почти 60\% мужчин ещё не состояли в браке, в то время как в 1897 г. в данной возрастной группе доля не вступавших в брак женщин составляла лишь $21 \%$, а мужчин - 44\%. В то же время снижение прочности брачных союзов нашло отражение в тенденции к росту разводимости: в каждой из выделенных половозрастных групп доля разведённых в 2010 г. на порядок превышает долю разведённых в соответствующей возрастной группе 1897 г. Как показывают исследования [Захаров 2013], риск прекращения брака в России повышается. Так, по данным переписи 1989 г. на 1000 женщин приходилось 84 разведённых (разошедшихся) женщины (для мужчин соответственно 57 на 1000), в то время как в 2010 г. на 1000 женщин пришлось уже 121 разведённых (разошедшихся), для мужчин - 78 на 1000. Разводы, повторные браки, незарегистрированные союзы усложняют семейную структуру и снижают прочность 
семейных связей [Kaneko 2007; Gaymu et al. 2008; Keilman, Christiansen 2010], что предопределяет специфику межпоколенных обменов. Развод родителей негативно сказывается на отношениях со взрослыми детьми, что ведёт к снижению масштабов межпоколенных обменов [Pezzin, Schone 1999: 287-297]. Например, взрослые дети реже помогают своему отцу, если он находится в разводе с их матерью [Hogan et al. 1993: 14281458]. Для мужчин риск ухудшения отношения с детьми после развода выше, чем для женщин [Furstenberg et al. 1995], поэтому в старости разведённые отцы подвержены высокому риску остаться без поддержки со стороны детей. Негативные изменения в отношениях, проявляющиеся в снижении частоты контактов и сокращении трансфертных потоков, характерны и для отношений между взрослыми детьми и матерями, повторно вступившими в брак. Кроме того, повторные браки родителей расширяют потенциальную сеть частных трансфертов: мачехи и отчимы могут играть важную роль в жизни неродных детей, которые, повзрослев, будут сохранять с ними связи.

Таблица 3. Распределение населения по полу, возрасту и состоянию в браке, 1897,2010

\begin{tabular}{|c|c|c|c|c|c|c|c|c|c|c|c|c|c|c|c|c|}
\hline \multirow[b]{3}{*}{ Возраст, лет } & \multicolumn{4}{|c|}{ Холост/не замужем } & \multicolumn{4}{|c|}{ В браке } & \multicolumn{4}{|c|}{ Вдовец/вдова } & \multicolumn{4}{|c|}{ Разведён/разведена } \\
\hline & \multicolumn{2}{|c|}{ муж } & \multicolumn{2}{|c|}{ жен } & \multicolumn{2}{|c|}{ муж } & \multicolumn{2}{|c|}{ жен } & \multicolumn{2}{|c|}{ муж } & \multicolumn{2}{|c|}{ жен } & \multicolumn{2}{|c|}{ муж } & \multicolumn{2}{|c|}{ жен } \\
\hline & 1897 & 2010 & 1897 & 2010 & 1897 & 2010 & 1897 & 2010 & 1897 & 2010 & 1897 & 2010 & 1897 & 2010 & 1897 & 2010 \\
\hline $\begin{array}{l}(15)^{1} \\
16-19\end{array}$ & 95,5 & 98,2 & 84,1 & 92,2 & 4,5 & 1,74 & 15,8 & 7,5 & 0,02 & 0,02 & 0,10 & 0,04 & 0,01 & 0,08 & 0,03 & 0,32 \\
\hline $20-29$ & 44,4 & 59,2 & 20,9 & 41,8 & 54,9 & 37,6 & 77,5 & 51,5 & 0,60 & 0,07 & 1,36 & 0,45 & 0,06 & 3,18 & 0,14 & 6,27 \\
\hline $30-39$ & 9,5 & 17,2 & 6,5 & 12,2 & 88,6 & 71,6 & 87,9 & 70,1 & 1,70 & 0,41 & 5,36 & 2,20 & 0,11 & 10,72 & 0,18 & 15,53 \\
\hline $40-49$ & 4,3 & 7,1 & 4,6 & 5,8 & 91,4 & 78,9 & 80,7 & 68,9 & 4,10 & 1,37 & 14,42 & 6,71 & 0,13 & 12,64 & 0,17 & 18,61 \\
\hline $50-59$ & 3,0 & 4,0 & 4,3 & 4,1 & 87,1 & 82,1 & 66,0 & 62,9 & 9,80 & 3,52 & 29,40 & 16,45 & 0,13 & 10,40 & 0,15 & 16,58 \\
\hline 60 и более & 2,6 & 1,7 & 4,8 & 3,5 & 68,0 & 76,2 & 36,2 & 33,7 & 29,00 & 16,80 & 58,50 & 53,77 & 0,13 & 5,29 & 0,14 & 9,03 \\
\hline
\end{tabular}

Источник: [Перепись Российской Империи... 1905; Всероссийская перепись населения 2010].

Одно из последствий развода связано с появлением неполной семьи. В 2010 г. в России доля неполных семей, т.е. домохозяйств, состоящих из матери (отца) с детьми, составила 15,6\%. Данный тип является вторым по распространённости среди частных домохозяйств, состоящих из двух и более человек. Одна из важнейших проблем неполных семей заключается в том, что положение детей в таких семьях нестабильно, так как снижается уровень их экономической защищённости. Чаще всего одинокий родитель (как правило, мать) не может обеспечить такой уровень благосостояния, который достигается в полной семье. Проживание в неполной семье повышает риск бедности. Неполные семьи выступают активными акцепторами частных трансфертов. Как показывают исследования, более половины таких семей получают материальную поддержку от родственников, 20\% из них получают её на регулярной основе [Овчарова, Прокофьева 2000: 23].

Члены родственной группы могут проживать вместе или раздельно. Если родственники отделяются друг от друга, образуя разные домохозяйства, то структура домохозяйства упрощается, происходит нуклеаризация. Если родственники наоборот объединяются в одно домохозяйство, то происходит усложнение его структуры. Преобладание простых нуклеарных семей - одна из главных характеристик семейной структуры российского населения. Нуклеарная семья, состоящая из родителей (одного родителя) и детей либо только из супругов, как правило, противопоставляется

\footnotetext{
${ }^{1}$ В переписи 1897 г. данные о состоянии в браке приводятся с 15 лет, а в переписи 2010 г. - с 16 лет.
} 
патриархальной семье традиционного типа, которая включает представителей нескольких взрослых поколений. Переход к нуклеарной семье, обусловленный процессами индустриализации и урбанизации, начался в России ещё в XX веке (начиная с конца 1920х годов размер семьи начал быстро сокращаться), однако и в настоящее время нельзя говорить о его завершённости [Вишневский 2008]. Одной из причин упрощения структуры домохозяйств может выступать повышение пространственной мобильности населения. Если по данным переписи 1926 г. 96\% постоянного населения являлось уроженцами тех регионов, где они проживали на момент переписи, то в 2002 г. - 71\%. Вследствие миграции детей, которые в основном уезжают для того, чтобы получать образование и устраиваться на работу, родители в старости зачастую остаются одинокими и нуждаются в поддержке. В то же время внутрисемейные трансферты сами могут выступать причиной миграции. Например, когда пожилые люди, нуждающиеся в постоянной опеке, мигрируют в населённые пункты, где живут их дети, можно говорить о восходящих межпоколенных трансфертах.

В процессе нуклеаризации происходит территориальное разделение членов родственной группы (например, взрослые дети живут отдельно от пожилых родителей). Парсонс структурную изоляцию членов семьи, их проживание в отдельных домохозяйствах позиционирует как важнейшую причину отмирания традиционных механизмов родственной межпоколенной поддержки [Parsons 1955: 10-26]. Среди основных характеристик нуклеарной семьи Парсонс [Parsons 1955] отмечает её изолированность. Изолированность проявляется в том, что члены нуклеарной семьи живут обособленно от других родственников, а также ведут независимое экономическое существование. Некоторые исследователи [Ружже, Кадибур, Елисеева 1976] считают, что при такой семейной организации первичными становятся отношения между супругами (представителями одного поколения), а отношения между представителями разных поколений уходят на второй план. В свою очередь нуклеарная семья сокращается в условиях снижения рождаемости, что делает связи внутри неё всё более тесными.

Однако фактически вместо обособленных чисто нуклеарных семей появляется модифицированная расширенная семья, члены которой тесно связаны между собой взаимными обменами помощью [Litwak 1960]. Таким образом, процесс нуклеаризации сопровождается обратным явлением: формированием родственных групп, внутри которых поддерживаются тесные связи [Волков 1996]. С социологической точки зрения семья остается таковой и после территориального разделения, если продолжается единая общесемейная деятельность ее членов, которая является одним из основных признаков семьи. Если в семье из трех поколений сохраняются все отношения взаимопомощи, несмотря на то, что представители среднего и младшего поколения проживают отдельно от представителей старшего поколения, то само их разделение можно назвать полной нуклеаризацией семей только в демографическом, но не в социологическом смысле, поскольку территориальная нуклеаризация не сопровождается функциональной. Понятие «модифицированная расширенная семья» близко к понятию «семейная группа», под которой понимается группа домохозяйств, члены которых находятся в родстве или свойстве и имеют общие материальные интересы, объединены морально- 
психологическими и эмоциональными отношениями, заинтересованы во взаимной помощи и общении.

\section{ЗАКЛЮЧЕНИЕ}

В результате происходящих демографических изменений (увеличение продолжительности жизни, снижение рождаемости, рост разводимости и повторных браков и др.) происходит существенная трансформация внутрисемейных межпоколенных взаимодействий. В данном случае мы согласны с Бенгтсоном [Bengtson 2001], который утверждает, что в связи с происходящими с середины XX века демографическими изменениями:

- $\quad$ межпоколенные связи (в которые теперь вовлечены 3 и более поколений) играют всё более важную роль для отдельных лиц и семей в целом;

- межпоколенные взаимодействия между членами семейной группы становятся для индивидов важнее, чем связи в нуклеарной семье;

- межпоколенные взаимоотношения становятся всё более сложными по структуре и выполняемым функциям [Bengtson 2001].

Изменение демографического контекста межпоколенных отношений (изменение возрастной семейной структуры, увеличение числа одновременно живущих поколений и длительности периода совместного проживания поколений в историческом пространстве) увеличивает возможности и потребности для взаимодействий, поддержки и взаимного влияния представителей более чем двух поколений. Наблюдается усиление межпоколенной солидарности и увеличение многообразия типов межпоколенной поддержки. Хотя наряду с этим усиливается и проблема межпоколенных конфликтов, что, однако, не снижает прочности семейных связей.

Удлиняется период совместного проживания разных поколений в одном историческом времени. Это означает рост потенциала поддержки для молодого поколения за счёт того, что в случае необходимости они могут обратиться, например, к своим прародителям. В то же время это может означать, что со стороны старшего поколения увеличится спрос на поддержку.

Повышение нестабильности нуклеарной семьи (распространение разводов, повторных браков) на протяжении последних десятилетий ведёт к тому, что нуклеарная семья не может быть надёжным оплотом в обеспечении социализации и поддержки для членов семьи. Некоторые исследователи считают, что снижение роли нуклеарной семьи в современном обществе является наиболее серьёзным, чем когда бы то ни было [Роpenoe 1993]. Современная нуклеарная семья сильно отличается своей нестабильностью от традиционной нуклеарной семьи, где главой семьи являлся мужчина, что во многом связано с процессом женской эмансипации. В связи с этим именно поддержка за счёт родственников, принадлежащих к разным поколениям, будет выступать в качестве основной опоры для индивида в XIX веке. 


\section{ОГРАНИЧЕНИЯ ИССЛЕДОВАНИЯ}

Отсутствие эмпирических данных о частных межпоколенных трансфертах за длительный период не позволяет проиллюстрировать обсуждаемые в статье тенденции с точки зрения эмпирического анализа.

\section{ЛИТЕРАТУРА}

Барсукова С.Ю. (2004). Нерыночные обмены между российскими домохозяйствами: теория и практика реципрокности // Препринт WP4/2004/02. Серия WP4. Социология рынков. М.: ГУ-ВШЭ.

Вишневский А.Г. (2005). Похвала старению // Отечественные записки. 3(24). URL: http://www.strana-oz.ru/2005/3/pohvala-stareniyu (дата обращения: 12.04.2016).

Вишневский А.Г. (2008). Эволюция российской семьи // Экология и жизнь. 8: 8-13.

ВНДН (2012). Выборочное наблюдение доходов населения и участия в социальных программах - 2012. М.: Росстат. URL:

http://www.gks.ru/free_doc/new_site/USP/survey0/data/description.pdf (дата обращения: 12.04.2016).

Волков А. (1996). Семейная структура населения России: факторы и тенденции // Российский демографический журнал. 1.

Всероссийская перепись населения 2010 (2010). М.: Росстат. URL: http://www.gks.ru/free_doc/new_site/perepis2010/croc/perepis_itogi1612.htm (дата обращения: 12.04.2016).

Денисенко М.Б. (2005). Тихая революция // Отечественные записки. №3 (23). URL: http://www.strana-oz.ru/2005/3/tihaya-revolyuciya (дата обращения: 12.04.2016).

Захаров С.В. (2005). Перспективы рождаемости в России: второй демографический переход // Отечественные записки. №3(24). URL: http://www.stranaoz.ru/2005/3/perspektivy-rozhdaemosti-v-rossii-vtoroy-demograficheskiy-perehod (дата обращения: 12.04.2016).

Захаров С.В. (2013). Куда движется супружество в России? // Демоскоп Weekly. №545546. URL: http://demoscope.ru/weekly/2013/0545/tema06.php (дата обращения: 01.09.2015).

Зидер Р. (1997). Социальная история семьи в Западной и Центральной Европе (конец 1820 вв.). М.: Гуманитарный издательский центр ВЛАДОС.

Котликофф Л., С. Бёрнс (2005). Пенсионная система перед бурей: то, что нужно знать каждому о финансовом будущем своей страны. Пер. с англ. М.: Альпина Бизнес Букс. $348 \mathrm{c}$.

Лежнина Ю. П. (2010). Социально-демографические факторы, определяющие риск бедности и малообеспеченности // Социологические исследования. 3: 36-45.

Никитенко В.В. (1979). Демографический анализ поколений. М.

Овчарова Л., Л. Прокофьева (2000). Бедность и межсемейная солидарность в России в переходный период // Мониторинг общественного мнения. 4(48). 
Первая всеобщая перепись населения Российской Империи 1897 года (1905). Общий свод по империи результатов разработки данных первой всеобщей переписи населения, произведенной 28 января 1897 г. Т.1, 2. СПб.: ЦСК.

Приложение Демоскоп Weekly (2016). Ожидаемая продолжительность жизни при рождении, 1960-2013 (лет). URL: http://demoscope.ru/weekly/app/app40e0.php; Средний возраст матери при рождении первого ребенка, 1950-2012. URL:

http://demoscope.ru/weekly/app/app40acb1.php (дата обращения: 12.04.2016).

Распределение малоимущего населения по основным группам по материалам выборочного обследования бюджетов домашних хозяйств (2012). М.: Росстат. URL: http://www.gks.ru/free_doc/new_site/population/urov/urov_53.htm (дата обращения: 01.09.2015).

РМЭЗ (2013). Российский мониторинг экономического положения и здоровья населения НИУ ВШЭ. URL: https://www.hse.ru/en/rlms/ (дата обращения: 12.04.2016).

Ружже В.Л., Т.С. Кадибур, И.И. Елисеева (1976). Структура и функции семейных групп. M.

Сови А. (1977). Общая теория населения. Т.2. Жизнь населений. Пер. с фран.. М.: Прогресс.

Тындик А.О. (2015). Москва на фоне России: результаты новейших исследований репродуктивного поведения населения // XV апрельская международная научная конференция по проблемам развития экономики и общества: в 4-х книгах / Отв. ред. Е.Г. Ясин. М.: Издательский дом НИУ ВШЭ.

Фрейка Т., С. Захаров (2014). Эволюция рождаемости в России за полвека: оптика условных и реальных поколений // Демографическое обозрение. 1(1): 106-143. URL: https://www.hse.ru/pubs/share/direct/document/135361911 (дата обращения: 12.04.2016).

Чаянов А.В. (1989). Крестьянское хозяйство. Избранные труды. М.: Экономика. 492 с.

Экономическая активность населения России - 2014 г. (2014). М.: Росстат. URL: http://www.gks.ru/bgd/regl/b14_61/Main.htm (дата обращения: 12.04.2016).

Alter G.C. (2013). Generation to generation life course, family, and community // Social science history. 37(1): 1-26.

Beard J., S. Biggs, D.E. Bloom, L.P. Fried, P.R. Hogan, A. Kalache, S.J. Olshansky (2012). Global population ageing: peril or promise? // Program on the global demography of aging. 8912.

Bengtson V.L. (2001) Beyond the nuclear family: the increasing importance of multigenerational bonds // Journal of marriage and family. 63(1): 1-16.

Bernheim B.D., A. Shleifer, L.H. Summers (1985). The strategic bequest motive // Journal of political economy. 93(6): 1045-1076.

Furstenberg F.F., S.D. Hoffman, L. Shrestha (1995). The effect of divorce on intergenerational transfers: new evidence // Demography. 32(3): 319-333.

Gaymu J., P. Festy, M. Poulain, G. Beets (2008). Future elderly living conditions in Europe // Les cahiers de l'INED. Paris: INED. 162 p.

Hogan D.P., D.J. Eggebeen, C.C. Clogg (1993). The structure of intergenerational exchanges in American families // American journal of sociology. 98(6): 1428-1458. 
Kaneko R. (2007). Population prospects of the lowest fertility with the longest life: the new official population projections for Japan and their life course approaches // Work session on demographic projections, Bucharest, Luxembourg: EUROSTAT Methodology and working papers, Office for official publications of the European communities.

Keilman N., S. Christiansen (2010). Norwegian elderly less likely to live alone in the future // European journal of population. 26(1).

Kotlikoff L.J., A. Spivak (1981). The family as an incomplete annuities market // Journal of political economy. 89: 372-391.

Laslett P. (1990). A fresh map of life: the emergence of the third age. London. 213 p.

Laslett P. (1996). What is old age? Variation over the time and between cultures / G.Caselli, A.Lopez, eds. Health and mortality among elderly populations. Oxford: 21-38

Litwak E. (1960). Occupational mobility and extended family cohension // American sociological review. 25(3): 385-394.

Neugarten B.L. (1974). Age groups in American society and the rise of the young-old //The annals of the American academy of political and social science. 415(1): 187-198.

Parsons T. (1955). The American family: its relation to personality and to the social structure / T. Parsons, R. Bales. Family, socialization and interaction process. Glencoe: Free press: 1026.

Pezzin L.E., B.S. Schone (1999). Parental marital disruption and intergenerational transfers: an analysis of lone elderly parents and their children // Demography. 36(3): 287-297.

Popenoe D. (1993). American family decline, 1960-1990: a review and appraisal // Journal of marriage and the family. 55: 527-555.

Rozenzweig M. R. (1994). Transfers from parents to their adult children in the developed and the developing countries // Ageing and the family. New York: 195.

Sussman M., J. Cates, J. Smith (1970). The family and inheritance. Russell sage foundation.

Watkins S.C., J.A. Menken, J. Bongaarts (1987). Demographic foundations of family change // American sociological review. 52(3): 346-358. 


\title{
INFLUENCE OF DEMOGRAPHIC TRANSFORMATION IN THE SYSTEM OF PRIVATE INTERGENERATIONAL TRANSFERS
}

\section{ANNA MIRONOVA}

\begin{abstract}
This article discusses the implications of demographic changes for the system of private intergenerational transfers. It considers the basic demographic factors of private intergenerational transfers, including changes of the population age structure, the abundance of divorces and remarriages, the high level of migration activity and the process of nuclearization, and analyzes their influence on the system of private intergenerational transfers.
\end{abstract}

Key words: family, intergenerational transfers, interfamily transfers, demographic changes, households.

\begin{abstract}
Anna Mironova (amironova@hse.ru), National Research University Higher School of Economics, RusSia.
THE ARTICLE CHAPTER WAS PREPARED WITHIN THE FRAMEWORK OF THE BASIC RESEARCH PROGRAM AT THE NATIONAL RESEARCH UNIVERSITY HIGHER SCHOOL OF ECONOMICS (HSE) AND SUPPORTED WITHIN THE FRAMEWORK OF A SUBSIDY GRANTED TO THE HSE BY THE GOVERNMENT OF THE RUSSIAN FEDERATION FOR THE IMPLEMENTATION OF THE GLOBAL COMPETITIVENESS PROGRAM.
\end{abstract}

DATE RECEIVED: JUNE 2016.

\section{REFERENCES}

Alter G.C. (2013). Generation to generation life course, family, and community // Social science history. 37(1): 1-26.

Barsukova S. (2004). Nerynochnye obmeny mezhdu rossiiskimi domokhoziaistvami teoriia i praktika retciproknosti [Non-market exchanges between Russian households: the theory and practice of reciprocity] // Preprint WP4/2004/02. Seriia WP4. Sotciologiia rynkov Moscow: GU-VSHE [Working Paper WP4/2004/02. WP4 Series. Sociology of Markets. Moscow: HSE].

Beard J., S. Biggs, D.E. Bloom, L.P. Fried, P.R. Hogan, A. Kalache, S.J. Olshansky (2012). Global population ageing: peril or promise? // Program on the global demography of aging. 8912.

Bengtson V.L. (2001). Beyond the nuclear family: The increasing importance of multigenerational bonds // Journal of marriage and family. 63(1): 1-16.

Bernheim B.D., A. Shleifer, L.H. Summers (1985). The strategic bequest motive // Journal of political economy. 93(6): 1045-1076.

Chaianov A.V. (1989). Krestianskoe khoziaistvo [Peasant economy]. Izbrannyie trudyi [Selected works]. Moscow: Ekonomika. 492 p.

Demoscope Weekly Supplement (2016). Ozhidaemaya prodolzhitelnost zhizni pri rozhdenii, 1960-2013 (let) [Life expectancy at birth, 1960-2013 (years)]. URL:

http://demoscope.ru/weekly/app/app40e0.php; Srednii vozrast materi pri rozhdenii pervogo rebenka, 1950-2012 [Average age at first birth, 1950-2012]. URL:

http://demoscope.ru/weekly/app/app40acb1.php (accessed: 12.04.2016).

Denisenko M.B. (2005). Tikhaia revoliutciia [Quiet Revolution] // Otechestvennye zapiski [Homeland Notes]. 3 (23). URL: http://www.strana-oz.ru/2005/3/tihaya-revolyuciya (accessed: 12.04.2016). 
Ekonomicheskaia aktivnost naseleniia Rossii - 2014 [Economic activity of Russian population 2014]. Moscow: Rosstat. URL: gks.ru (accessed: 12.04.2016).

Frejka T., S. Zakharov (2014). Evoliutciia rozhdaemosti v Rossii za polveka: optika uslovnykh i realnykh pokolenii [The evolution of fertility in Russia for half a century: conventional optics and real generations] // Demograficheskoe obozrenie [Demographic review]. 1(1): 106-143. URL: https://www.hse.ru/pubs/share/direct/document/135361911 (accessed: 12.04.2016).

Furstenberg F.F., S.D. Hoffman, L. Shrestha (1995). The effect of divorce on intergenerational transfers: new evidence // Demography. 32(3): 319-333.

Gaymu J., P. Festy, M. Poulain, G. Beets (2008). Future elderly living conditions in Europe // Les cahiers de l'INED. 162. Paris: INED. 162 p.

Hogan D.P., D.J. Eggebeen, C.C. Clogg (1993). The structure of intergenerational exchanges in American families // American journal of sociology. 98(6): 1428-1458.

Kaneko R. (2007). Population prospects of the lowest fertility with the longest life: the new official population projections for Japan and their life course approaches // Work session on demographic projections, Bucharest, Luxembourg: EUROSTAT Methodology and working papers, Office for official publications of the European communities.

Keilman N., S. Christiansen (2010). Norwegian elderly less likely to live alone in the future // European journal of population. 26(1).

Kotlikoff L., C. Burns (2005). Pensionnaia sistema pered burei: to, chto nuzhno znat kazhdomu o finansovom buduschem svoey stranyi [The pension system before the storm: what everybody has to know about financial future of its country]. Trans. from English. M.: Alpina Business Books. 348 p.

Kotlikoff L.J., A. Spivak (1981). The family as an incomplete annuities market // Journal of political economy. 89: 372-391.

Laslett P. (1990). A fresh map of life: the emergence of the third age. London. 213 p.

Laslett P. (1996). What is old age? Variation over the time and between cultures / G. Caselli, A. Lopez, eds. Health and mortality among elderly populations. Oxford: 21-38

Lezhnina J.P. (2010). Sotcialno-demograficheskie faktory opredeliaiushchie risk bednosti i maloobespechennosti [Socio-demographic factors that determine the risk of poverty and poverty] // Sotciologicheskie issledovaniia [Sociological studies]. 3: 36-45.

Litwak E. (1960). Occupational mobility and extended family cohesion // American sociological review. 25(3): 385-394.

Neugarten B.L. (1974). Age groups in American society and the rise of the young-old //The annals of the American academy of political and social science. 415(1): 187-198.

Nikitenko V.V. (1979). Demograficheskii analiz pokolenii [Demographic analysis of generations]. Moscow.

Ovcharova L., L. Prokofieva (2000). Bednost i mezhsemeinaia solidarnost v Rossii v perekhodnyi period [Poverty and inter-family solidarity in Russia during the transition period] // Monitoring obshchestvennogo mneniia [Monitoring of public opinion]: 4(48).

Parsons T. (1955). The American family: its relation to personality and to the social structure / T. Parsons, R. Bales. Family, socialization and interaction process. Glencoe: Free Press: 10-26.

Pervaya vseobshchaya perepis' naseleniya Rossiiskoi Imperii 1897 goda [The First General Census of Russian Empire of 1897] (1905). Obshchii svod po imperii rezultatov razrabotki 
dannykh pervoi vseobshchei perepisi naseleniia proizvedennoi 28 ianvaria 1897 goda [General results of the elaboration of data of the Russian Empire first census carried out on January 28, 1897]. Vol.1, 2. Saint Petersburg: Central Statistical Committee.

Pezzin L.E., B.S. Schone (1999). Parental marital disruption and intergenerational transfers: an analysis of lone elderly parents and their children // Demography. 36(3): 287-297.

Popenoe D. (1993). American family decline, 1960-1990: A review and appraisal // Journal of marriage and the family. 55: 527-555.

Raspredelenie maloimushchego naseleniia po osnovnym gruppam po materialam vyborochnogo obsledovaniia biudzhetov domashnikh khoziaistv (2012). [Distribution of the poor by main groups according to a sample survey of household budgets]. Moscow: Rosstat. URL: www.gks.ru (accessed: 01.09.2015).

RMEZ [RLMS] (2013).The Russia longitudinal monitoring survey - Higher school of economics. URL: https://www.hse.ru/en/rlms/ (accessed: 12.04.2016).

Rozenzweig M.R. (1994). Transfers from parents to their adult children in the developed and the developing countries // Ageing and the family. New York: 195.

Ruzhzhe V.L., T.S. Kadibur, I.I. Eliseeva (1976). Struktura i funktcii semeinykh grupp [The structure and function of family groups]. M.

Sovi A. (1977). Obshchaia teoriia naseleniia [The general theory of population]. Vol. 2. Life of generations. Trans. with France. M.: Progress.

Sussman M., J. Cates, J. Smith (1970). The family and inheritance. Russell sage foundation.

Tyndik S.A. (2015). Moskva na fone Rossii rezultaty noveishikh issledovanii reproduktivnogo povedeniia naseleniia [Moscow against the background of Russia: results of the latest studies of reproductive behavior of the population] // XV the April International Academic Conference on Economic and Social Development: in 4 books / E. Yasin, ed. Moscow.: Publishing house of the HSE.

Vishnevsky A.G. (2005). Pokhvala stareniiu [Praise to aging] // Otechestvennye zapiski [Homeland notes]. 3(24). URL: http://www.strana-oz.ru/2005/3/pohvala-stareniyu (accessed: 12.04.2016).

Vishnevsky A.G. (2008). Evoliutciia rossiiskoi semi [Russian family evolution] // Ekologiia i zhizn [Ecology and life]. №8: 8-13.VNDN (2012).

Vyborochnoe nabliudenie dokhodov naseleniia i uchastiia v sotcialnykh programmakh - 2012 [Selective monitoring income and participation in social programs]. Moscow: Rosstat. URL: http://www.gks.ru/free_doc/new_site/USP/survey0/data/description.pdf (accessed: 12.04.2016).

Volkov A. (1996). Semeinaia struktura naseleniia Rossii: faktory i tendentcii [The family structure of the Russian population: factors and trends] // Rossiiskii demograficheskii zhurnal [Russian demographic journal]. 1.

Vserossiiskaia perepis naseleniia - 2010 (2010) [Russian Population Census - 2010]. Moscow: Rosstat. URL: http://www.gks.ru/free_doc/new_site/perepis2010/croc/perepis_itogi1612.htm (accessed: 12.04.2016).

Watkins S.C., J.A. Menken, J. Bongaarts (1987). Demographic foundations of family change // American sociological review. 52 (3): 346-358.

Zakharov S.V. (2005). Perspektivy rozhdaemosti v Rossii: vtoroi demograficheskii perekhod [Birth prospects in Russia: the second demographic transition] // Otechestvennye zapiski 
[Homeland Notes]. №3 (24). URL: http://www.strana-oz.ru/2005/3/perspektivyrozhdaemosti-v-rossii-vtoroy-demograficheskiy-perehod (accessed: 12.04.2016).

Zakharov S.V. (2013). Kuda dvizhetsia supruzhestvo v Rossii? [Where is marriage in Russia?] Demoscope weekly. №545-546. URL: http://demoscope.ru/weekly/2013/0545/tema06.php (accessed: 01.09.2015).

Zider R. (1997). Sotcialnaia istoriia semi v Zapadnoi i Tcentralnoi Evrope (konetc 18-20 vv.) [The social history of the family in Western and Central Europe (end of 18-20 centuries)]. M.: Publishing center for humanities VLADOS. 